\title{
Total diz protezinde biyomateryaller ve protez tasarımları
}

\author{
Biomaterials and prosthesis design in total knee replacement
}

\author{
Mahmut Özdemir ${ }^{1}$, Ertuğrul Akşahin² \\ ${ }^{1}$ Ankara VM Medikal Park Hastanesi, Ankara \\ ${ }^{2}$ Yüksek İhtisas Üniversitesi Tıp Fakültesi, Ortopedi ve Travmatoloji Ana Bilim Dalı; Ortopedi Ankara Kliniği, Ankara
}

\begin{abstract}
Son evre diz artrozunun altın standart tedavisi diz artroplastisidir ve sayısı gittikçe artış göstermektedir. Diz protezi uygulamalarının başarısını etkileyen belki de en önemli husus implant kalitesi ve bu implantların biyomekanik uyumudur. İdeal bir biyomateryalin elastik modülüsü kemiğin elastik modülüsüne yakın olmalıdır. Bu materyal aynı zamanda aşınma ve korozyona dirençli ve biyolojik olarak uyumlu bir yapıya sahip olmak zorundadır. Bir diz protezinde femoral, tibial ve patellar olmak üzere üç farklı komponent bulunmaktadır. Bu komponentlerden tibial ve femoral komponentler, kobalt-krom, titanyum ve paslanmaz çelik gibi sert metal alaşımlardan oluşmaktadır. Bu komponentlerin uyumunu sağlayan ara yüzeyler ve çoğu patellar komponent ise polietilen yapıdadır. Primer diz protezi arka çapraz bağın korunmasına veya kesilmesine göre gruplandırılır, çimento yardımıyla veya çimentosuz bir şekilde uygulanabilir. Polietilen ara yüzeyler ise sabit veya hareketli olabilmektedir. Seramik yüzeylerin, yüksek fleksiyon kapasiteli (high-flex) tasarımların, cinsiyet spesifik protez tiplerinin ve özellikle tantalum uygulanan çimentosuz protez tasarımlarının kullanımı her geçen gün artmaktadır.

Anahtar sözcükler: total diz protezi; biyomateryaller; tasarım
\end{abstract}

\begin{abstract}
Knee arthroplasty is the gold standard treatment for endstage gonarthrosis and its volume is increasing constantly. The most important issue affecting the success of knee prosthesis is implants quality and biomechanical compatibility. In an ideal biomaterial, the elastic modulus should be close to the bone. This material also have to be wear and corrosion resistant and biocompatible. There are three components in a knee prosthesis design: femoral, tibial and patellar components. The tibial and femoral components consist of hard metal alloys such as cobalt-chromium, titanium and stainless steel. Intermediate structures that support the compatibility of these components and most patellar components are in polyethylene structure. Primary knee replacements are classified according to the preservation or sacrification of the posterior cruciate ligament and could be applied with or without cement. Polyethylene insert can be fixed or mobile. The use of ceramics, highflex designs, gender-specific prosthesis types, and especially tantalum-applied cementless prosthesis designs are increasing.
\end{abstract}

Key words: total knee prosthesis; biomaterials; design

Canlı bir dokuya destek sağlamak veya canlı bir dokunun yerini doldurmak amacıyla biyolojik sistemle uyum içinde kullanılacak cansız materyaller biyomateryal olarak tanımlanmaktadır. ${ }^{[4]}$ ideal bir biyomateryal, kemiğin elastik modülüsüne yakın, aşınma ve korozyona dirençli ve biyolojik olarak uyumlu bir yapıya sahip olmalıdır. ${ }^{[5]}$ Yeterli direnci olmayan bir implantta yetmezlik kırıkları, elastik modülüsü kemiğe yakın olmayan bir implantta stres kalkanı ve kemik destrüksiyonu, aşınma ve korozyona dirençli olmayan bir implantta ise yine gevşemenin yanında metalik iyonların dolaşıma geçmesi ve çeşitli sistemik reaksiyonlar görülebilmektedir. ${ }^{[5]}$ Biyolojik uyumun, mekanik uyumun ve osteointegrasyonun olmadığı bir durumda implant yetmezliği kaçınılmazdır.

iletişim / Contact: Prof. Dr. Ertuğrul Akşahin • E-posta / E-mail: ertugrul_Aksahin@hotmail.com

ORCID iD: Mahmut Özdemir, 0000-0003-2674-9549 • Ertuğrul Akşahin, 0000-0001-5771-8476

Geliş / Received: 12 Temmuz 2021 • Kabul / Accepted: 30 Temmuz 2021 


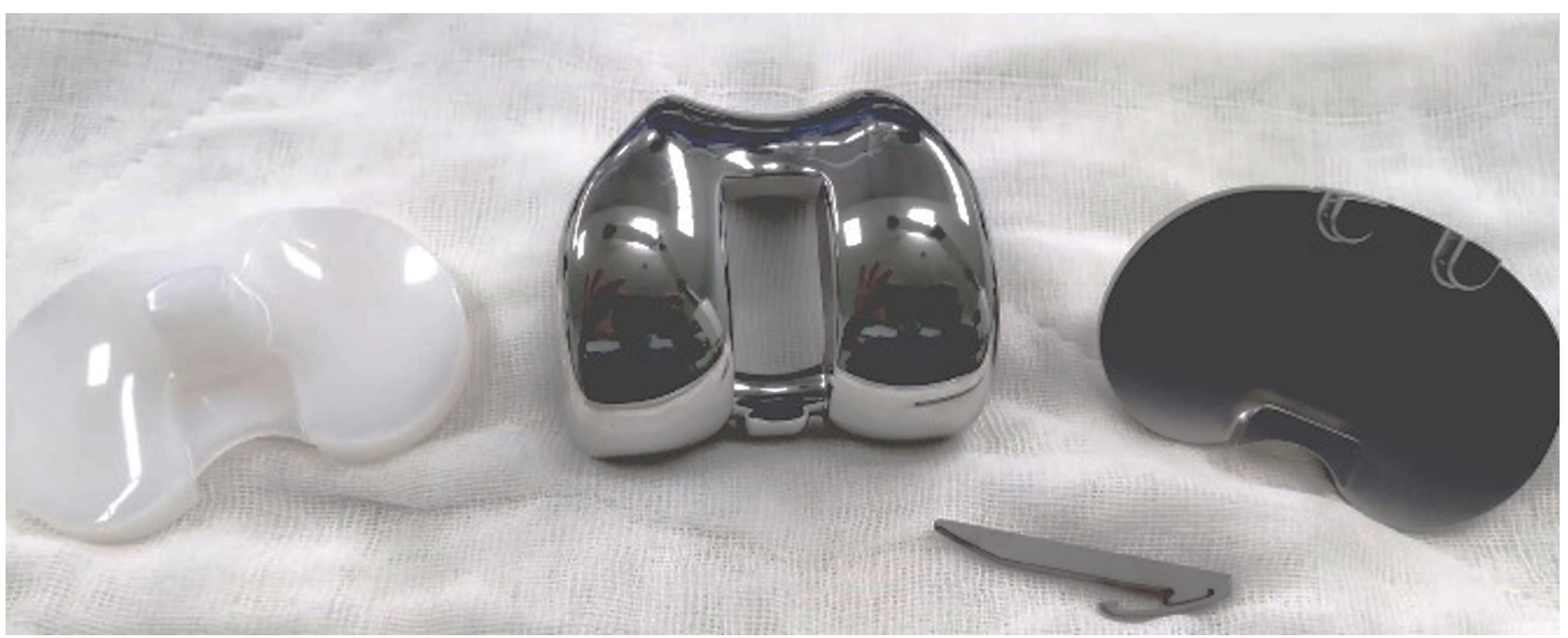

Şekil 1. Kobalt-krom alaşım diz protezi komponentleri.

\section{TOTAL DIZ PROTEZINDE BIYOMATERYALLER}

Bir trikompartmantal diz artroplasti sisteminde temelde femoral, tibial ve patellar olmak üzere üç farkIı komponent bulunmaktadır. Bu komponentlerden tibial ve femoral komponentler, başta kobalt-krom (Co-Cr) olmak üzere titanyum $(\mathrm{Ti})$ ve paslanmaz çelik gibi sert metal alaşımlardan oluşmaktadır. ${ }^{[6]}$ Bu komponentlerin uyumunu sağlayan ara yapılar (insert) ve çoğu patellar komponent ise çapraz bağlı veya yüksek yoğunluklu polietilen yapıdan oluşmaktadır. ${ }^{[7]}$

\section{Kobalt-Krom Alaşımlar}

Protez cerrahisinde günümüzde hâlâ en sık kullanılan alaşım krom kobalt alaşımlardır. Kobalt, krom ve molibden (Co-Cr-Mo) ve kobalt, nikel, krom, molibden (Co-Ni-Cr-Mo) olmak üzere iki farklı tip alaşım en yaygın kullanılan kobalt-krom alaşımlarıdır. ${ }^{[5]} \mathrm{Bu}$ alaşımların kritik noktası, insan vücudu ile temas ettiğinde oluşturdukları spontan okside tabakadır. Bu sayede diğer alaşımlara kıyasla korozyona karşı oldukça dirençlidirler. ${ }^{[8]}$ Ayrıca yaklaşık \%8 uzayabilme kapasiteleri sayesinde kırılgan özellik taşımazlar. Tüm bu özellikleri bu alaşımları, günümüzde, elastik modülüslerinin çelikten bile yüksek olmalarına ve nikel, kobalt gibi toksik artık oluşturmalarına rağmen, ortopedi ve travmatoloji alanındaki implant imalatının en yaygın materyalleri haline getirmiştir (Şekil 1)..$^{[9]}$

\section{Paslanmaz Çelik}

Ortopedi ve travmatoloji alanında, özellikle travma cerrahisinde kendine yer bulan çelik, içeriğindeki karbon yoğunluğuna göre düşük, orta, yüksek ve takım çelikleri olmak üzere dört gruba ayrılır ve kullanım alanlarına göre çeşitli sınıflara ayrılır. ${ }^{[10]}$ İmplant sektöründe kullanılan paslanmaz çelik ise \%10-\%25 oranında krom ihtiva eder. Kromun yüzeye çıkıp oksitlenmesiyle oluşan krom oksit paslanmayı engeller. Biyouyumluluğu oldukça yüksektir fakat korozyona dirençleri diz protezinde kullanılan diğer alaşımlara nazaran daha düşüktür. Korozyona direnci artırmak için nikel veya manganez eklenip güçlendirme çalışmaları denenmiş fakat yeterli gelişme sağlanamamıştır. ${ }^{[5]}$ Korozyon nedeniyle oluşan yorgunluk kırıkları ve çatlaklar, implant yetmezliğinin yanında sistemik dolaşıma debris geçişine ve dolayısıyla çeşitli sistemik ve alerjik reaksiyonların görülmesine neden olmaktadır. ${ }^{[11]}$ Diğer yandan çelik alaşımların elastik modülüsü kemiğin çok üzerindedir (200 gpa -20 gpa) ve bu durum stres kalkanı ve yetmezliklere zemin hazırlamaktadır. Tüm bu nedenler yüzünden protez cerrahisinde paslanmaz çeliğin kullanımı alanı oldukça dardır.

\section{Titanyum Alaşımlar}

Yirminci yüzyılın başlarında üretilmeye başlayan titanyum alaşımlar günümüzde ortopedi ve travmatoloji alanında, sert yapıları ve oluşturdukları titanyum oksit tabakası sayesinde korozyona dirençli özellikleri, biyolojik uyumlulukları ve diğer alaşımlara nazaran kemiğe yakın elastik modülüsleri sayesinde oldukça popüler hale gelmiştir. Ti-6Al-4V alaşımı ve saf titanyum, implant uygulamalarında en sık kullanılan çeşitleridir. ${ }^{[12]}$ Fakat avantajlarının yanında, kobalt-krom ve çelik alaşımlarla kıyaslandığında aşınma miktarı fazladır ve protez komponenti olarak uzun dönem kullanımları 
sonucunda özellikle nöropati ve Alzheimer hastalığının etiyolojisinde suçlanan alüminyum ve vanadyum iyonlarının sistemik dolaşıma yayıldığı gösterilmiştir. ${ }^{[13]}$ Gelişen teknoloji ile üretilmiş yeni jenerasyon titanyum alaşımları (Ti-35Nb-7Zr-5Ta, Ti-29Nb-13Ta-4.6Zr) güçlü yapıları, kemiğe yakın elastik modülüsleri ve korozyona dirençli yapıları sayesinde protez cerrahisinde kendilerine daha fazla yer bulacaklardır. ${ }^{[14]}$

\section{Seramik Yüzeyler}

Kalça protezinde uzun süredir kullanılan ve oldukça başarılı olan seramik yüzey seçenekleri diz artroplastisinde de kullanılmaya başlanmıştır. ${ }^{[15]}$ Yekpare seramik yüzey şeklinde üretilebildikleri gibi kemik temas yüzeyi metal, eklem yüzeyi seramik şeklinde imal edilen implantlar da mevcuttur. Yüzey özellikleri seramikleri gerek yüzey ve gerekse polietilen aşınmaya en dayanıklı yapılar haline getirmektedir. Buna karşın özellikle diz ekleminin öne arkaya, döngüsel ve atlama hareketleri ile birlikte değerlendirildiğinde kırılganlıklarının fazla olması büyük dezavantajdır. Aluminya ve zirkonya kaplamalar en yaygın kullanılan seramik yüzey seçenekleridir. Son dönemde okside zirkonyum formu oksinyum yüzey, kalça protezlerinden sonra dizde de kullanılmaya başlanmıştır. ${ }^{[15]}$

\section{Polietilen Ara Yüzeyler}

Protez komponentleri arasında mekanik uyumun sağlanabilmesi ve uzun sağkalım için menisküs benzeri ara yapıların olması gerekmektedir. Trikompartmantal diz artroplasti sisteminin patellar komponent yapısını da oluşturan bu madde, etilen kullanılarak oluşturulan bir termoplastik şeklinde imal edilir. Bu yapı polietilen (PE) olarak isimlendirilir. İmplant sektöründe kullanılan klasik polietilen yapılar yerlerini aşınmaya daha dayanıklı olan yüksek molekül ağırıłklı polietilene (UHMWPE, ultra high molecular weight polyethylene) bırakmıştır. ${ }^{[16]}$ Polietilen sterilizasyonu raf ömrü ve dayanıklılıkta kritik rol oynamaktadır. Klasik gama radyasyon, oluşan serbest radikaller nedeniyle polietilenin yapısal dayanıklılığını azaltmaktadır fakat bu esnada oluşan çapraz bağlar aşınmaya karşı direnç oluştururlar. Bu nedenle etilen oksit ile sterilizasyona nazaran daha çok kullanılmaktadır. Hatta UHMWPE'den daha dayanıklı olduğu gösterilmiş XLPE (X-linked polyethylene), polietilenin oksijensiz ortamda düşük doz gama radyasyon ve ısıtma yöntemiyle çapraz bağlarının artırılması suretiyle üretilmektedir. ${ }^{[17]}$ Polietilende diğer önemli hususlar raf ömrü ve polietilen kalınlığıdır. Raf ömrü uzadıkça aşınma direncinin azaldığı görülmüş̧ür. Bunun haricinde aşınma direnci için polietilen insert kalınlığının en az $8 \mathrm{~mm}$ olması gerekmektedir. ${ }^{[18]}$

\section{TOTAL DIZ PROTEZI TASARIMLARI}

Freeman ve ark.'nın belirttiği kriterlere göre ideal bir diz protezi işleminde; kemik stoğunu olabildiğince korumak, aşınma miktarını azaltacak materyaller kullanmak, gevşeme miktarını azaltacak önlemler almak, ölü boşluk oluşumunu ve dolayısıyla enfeksiyon oluşma riskini en aza indirmek, rutin standart bir cerrahi teknik kullanmak ve en az $90^{\circ}$ fleksiyon ve $5^{\circ}$ hiperekstansiyon elde etmek gerekmektedir. ${ }^{[19]}$

Günümüzde bu kriterlerin çoğu hâlâ önemini korumaktadır. Tarihsel gelişim boyunca olduğu gibi amaç dizin doğal biyomekaniğine en yakın eklemleşmeyi elde etmektir. Bunun için oldukça fazla farklı protez modelleri geliştirilmiş ve hâlâ da geliştirilmeye devam etmektedir (Tablo 1).

\section{Arka Çapraz Bağı Koruyan Diz Protezleri}

Diz eklemi hareketi esnasında çapraz bağların oluşturmuş olduğu dört bar sisteminde, fleksiyon esnasında bir geriye kayma (roll-back) ve rotasyon hareketi olmaktadır. Bu hareket için sağlam bir arka çapraz bağ $(A C ̧ B)$ veya onun görevini yapacak bir sistem olmak zorundadır. Arka çapraz bağın korunduğu protez tasarımında, ön çapraz bağ (ÖÇB) kesilirken AÇB kesilmez ve bu mekanizmasının devamı sağlanır. Sadece femur ve tibiadaki kireçlenmiş bölgeler uygun şekilde kesilir komponentler çimento yardımıyla veya çimentosuz bir şekilde implante edilir. Total diz protezi tasarımları içinde normal diz biyomekaniğine en yakın, en az kemik rezeksiyonu yapılan tasarım (dizayn) bağ koruyan tasarımlardır. ${ }^{[20]}$ Bu tip protezlerin avantajları içinde

Tablo 1. Yaygın total diz protezi tasarımı seçenekleri

\begin{tabular}{lll}
\hline & Diz protezi tasarımı çeşitleri & \\
\hline Sınırlayıcılık & AÇB koruyan & AÇB kesen \\
Ara yüzey seçenekleri & Sabit ara yüzey & Hareketli ara yüzey \\
Tespit seçenekleri & Çimentolu & Çimentosuz
\end{tabular}


propriyosepsiyon duyusunun korunması olduğu teorik olarak iddia edilse de yapılan çalışmalarda bu durum gösterilememiştir (Şekil 2). [21]

AÇB'nin korunduğu protezlerde bağın sağlamlığı ve gerginliği önemlidir. Gevşek bir arka çapraz bağ aşırı harekete ve gevşekliğe, olması gerektiğinden gergin bir bağ hareket kısıtlılığına ve sertliğe neden olmaktadır. Bu nedenle cerrahi esnasında AÇB gerginliği implantasyon öncesi her aşamada kontrol edilmelidir. ${ }^{[22]}$

Bağ koruyan tasarımlarda hareket açıklığını artırmak ve sıkışmayı engellemek için insert nispeten düzdür. Böyle tasarlanmış bir protezde mevcut AÇB'nin hasar görmesi ciddi gevşekliğe neden olacaktır. Bu nedenle yeni modellerde tibial plato uyumu artırılmış, ön dudak eklenmiş ve olası bir bağ yetmezliği durumunda aşırı translasyonun önüne geçilmeye çalışılımıştır. ${ }^{[23]}$

\section{Arka Çapraz Bağı Kesen Diz Protezleri}

Kesin bilimsel bir kural olmasa da özellikle görece genç hastalarda, ciddi kemik defekti veya ciddi yumuşak doku yetmezliği yoksa kemik stoğunu koruyucu bağ koruyan protez tasarımları tercih edilmekteydi. Yapılan çalışmalar, bağ koruyan diz protezi tercih edilmiş birçok hastada, mevcut arka çapraz bağın yeterli fonksiyona sahip olamadığını veya zaman içinde fonksiyonunu kaybettiğini göstermiştir. ${ }^{[24]}$ Bağ kesen protez tasarımların sınılayıcı yapısının teorik olarak gevşeme oranını artırdığı ileri sürülmüş fakat bilimsel olarak ispatlanamamıştır. Bağ koruyan protezlerde posterior sıkışmayı önlemek için polietilen insert daha

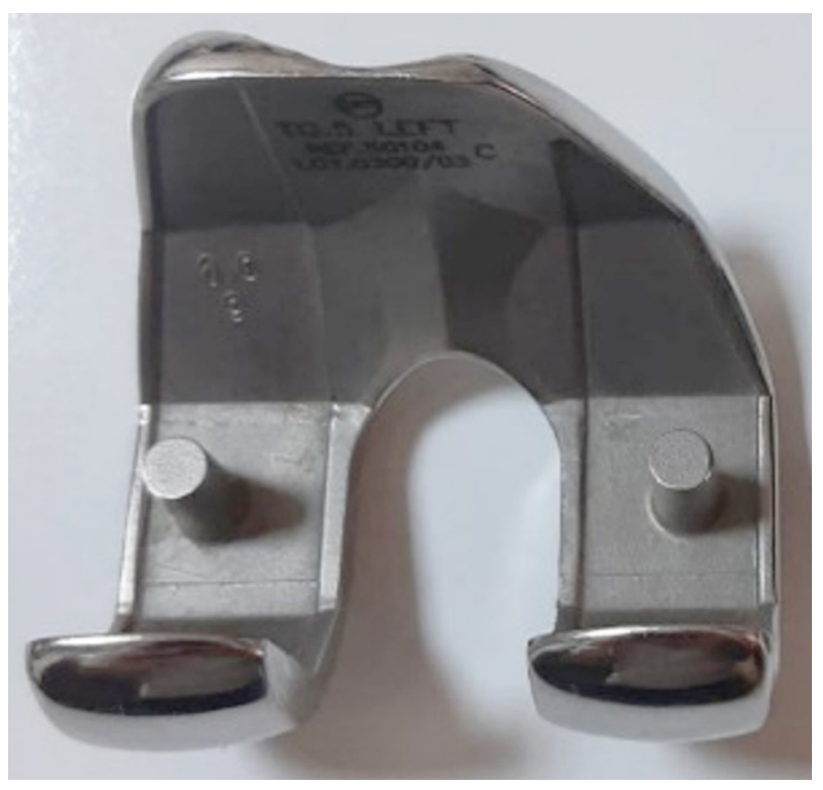

Şekil 2. AÇB koruyan femoral komponent tasarımı. düz bir şekilde tasarlanmıştır. Bağ kesen tasarımlarda ise böyle bir risk olmadığı için insert kondillere uyumlu derin ve konik bir şekilde imal edilebilmektedir. Bu özellik kondiler uyumu ve stabiliteyi artırmakta, atlama mesafesinin uzamasına bağlı olarak dislokasyon riskini azaltmakta, yüzey alanını artırmasına bağlı olarak stres yükünü ve temas basıncını azaltmakta ve dolayısıyla aşınmayı da azaltmaktadır. ${ }^{[25]}$

$\mathrm{Bu}$ tasarımda tibial komponentin polietilen yüzeyinin üzerinde bir çıkıntı (post) mevcuttur ve femoral komponent posterior kondiller arasında bir bağlantı mevcuttur (cam). Diz fleksiyonu esnasında tibial yüzeydeki çıkıntı, distal femurun interkondiler notch bölgesinde oluşturulmuş boşluğun içindeki hareketi sonunda femoral kondillerin birleşim yerindeki bağlantıya temas eder ve bu temas sonrasında geriye yuvarlanma hareketi gerçekleşir. Bu mekanizma tibianın posteriyora kaymasının önüne geçer, posterior sıkışmayı engeller ve fleksiyonu artırır. Gerek insert derinliği ve gerekse cam-post mekanizması sayesinde, bu tip protezlerde mediolateral stabilite daha fazladır (Şekil 3).

\section{TOTAL DiZ PROTEZINDE ARA YÜZEY SEÇIMi}

Diz protezinde komponentler arası uyumu ve sağkalımı artırmak için özel yapım polietilen yapılar kullanılmaktadır. Bu yapıların fiziksel ve kimyasal içeriklerinin yanında tasarımları ve yerleştirme şekilleri de önemlidir. Mekanik olarak değerlendirildiğinde temel olarak sabit ve hareketli olmak üzere iki farklı tipi mevcuttur (Şekil 4).

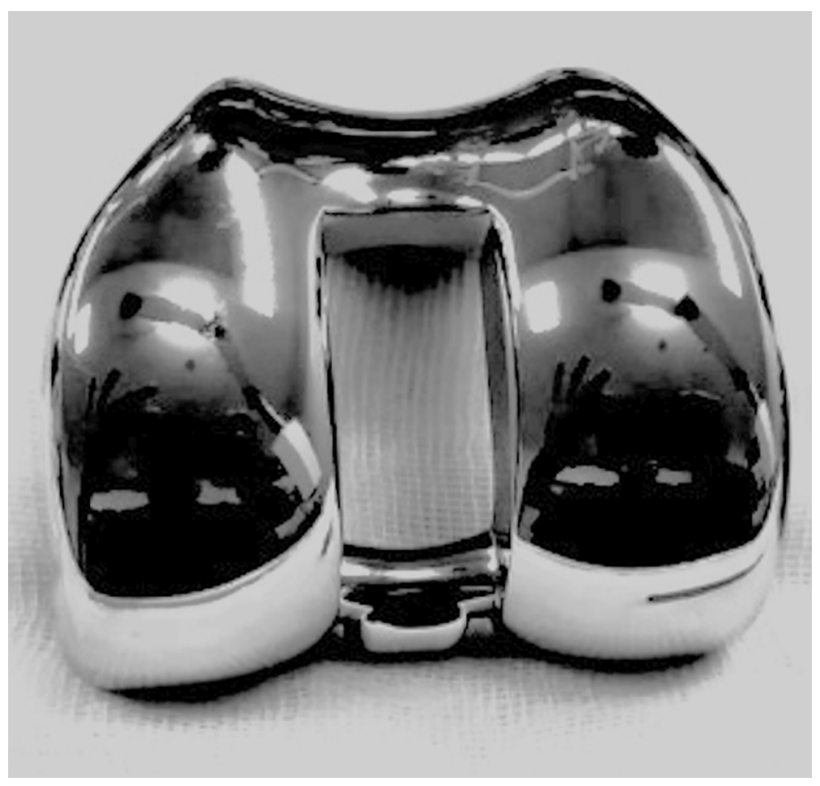

Şekil 3. AÇB kesen femoral komponent tasarımı. 


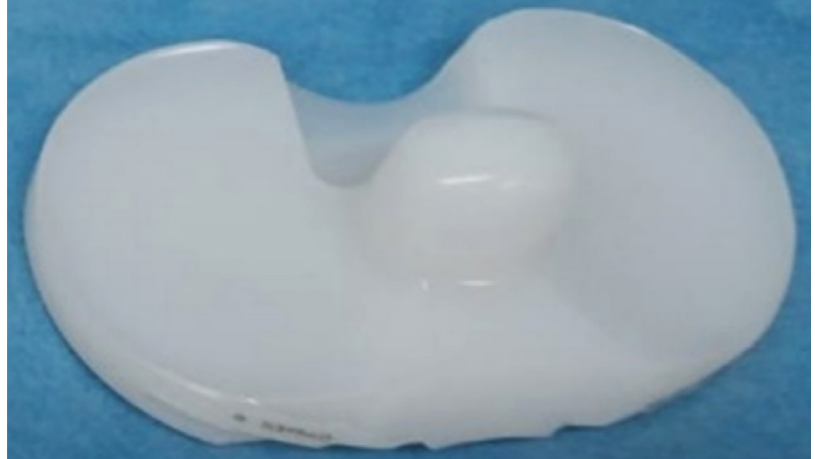

Şekil 4. Polietilen sabit ara yüzey (Arka çapraz bağ kesen protez için).

\section{Hareketli Ara Yüzeyler}

Polietilen yüzeylerin herhangi bir şekilde tibial komponente sabitlenmediği tasarımlardır. Yeni oluşturulan ekleme uygun tasarlanmış yapıları ve cerrahi işlem esnasında sağlanan yumuşak doku dengesi sayesinde eklem içinde kalarak fonksiyonellik kazanırlar. Hareketli olmaları nedeniyle eklem içini etkileyen torsiyonel ve rotasyonel kuvvetlere karşı daha az makaslamaya maruz kaldığı, tibial komponent ve kemik arasındaki stresin azaldığı ve bu nedenlerle hareketsiz olanlara kıyasla aşınmanın daha az gelişeceği öne sürülmüştür. Fakat yapılan çalışmalarda mekanik ve klinik sonuçlar veya aşınma açısından belirgin bir fark tespit edilememiştir. $^{[26]}$ Bu tip yüzeylerde hareket sadece döngüsel olarak olabildiği gibi bazı modellerde hem döngüsel hem de öne arkaya translasyonel şekilde olabilir. Çift taraflı hareketli sistemlerde aynı anda farklı yönlerden etkileyen streslerin olması nedeniyle aşınmanın daha fazla olacağı düşünülmekteydi. Fakat yapılan araştırmalar klinik olarak farklılık olmadığını ortaya koymuştur. ${ }^{[27,28]}$

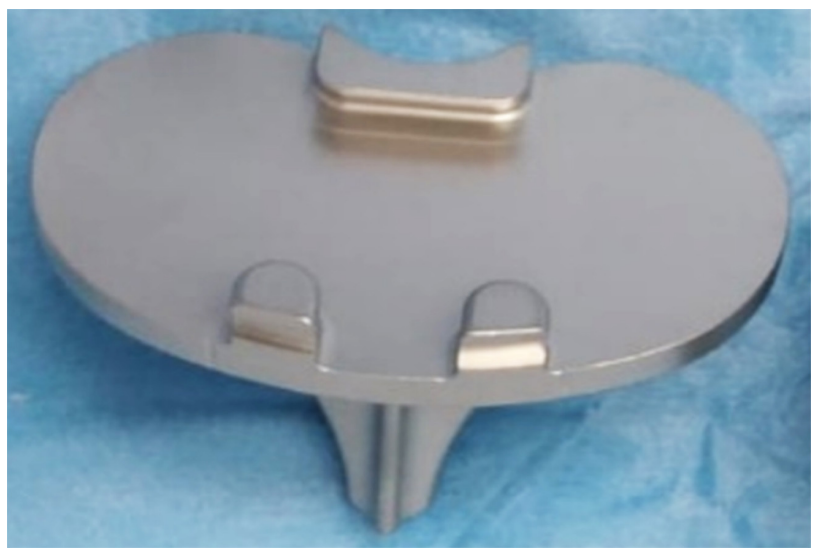

Şekil 5. Çimentolu tibial komponent eklem yüzeyi.

\section{Sabit Ara Yüzeyler}

Komponentler arası polietilen yüzey tibial komponente bir çentik yardımıyla ve/veya bir vida desteğiyle sabitleştirilir. Tibial komponentle birlikte hareket eden bu sistemde teorik olarak polietileni ve implant kemik bağlantısını etkileyen torsiyonel kurvetlerde artış olacağı ve bunun ara yüzeyin ömrünü kısaltacağı kaygısı mevcuttu. Fakat yapılan çalışmalarda böyle bir dezavantajın olmadığı gösterilmiştir. ${ }^{[29]}$ Bağ yetmezliğine veya travmaya bağlı polietilen dislokasyonu gibi komplikasyonların görülmemesi de avantajlarıdır.

\section{DiZ PROTEZINDE TESPIT}

Günümüzde kullanılan diz protezleri çimento yardımıyla veya implant içine kemik büyümesinin sağlandığı çimentosuz teknikle implante edilmektedir. Bu teknikler haricinde sadece tibial komponentin çimento yardımıyla implante edildiği hibrid teknik de az da olsa kullanılmaktadır.

Çimentolu diz protezi uygulaması, komponentlerin kemik yüzeylerine çimento uygulamasını takiben yapılan implantasyon tekniğidir ve günümüzde altın standarttır. Bu tekniğe uygun protezlerin kemik yüzeyi nispeten düzdür fakat yine de tutunumu artırmak için kumlama yöntemine başvurulmaktadır. Sağlamlığı ve dayanıklıı̆̆ı artırmak için kanat, oluk gibi çıkıntıları mevcuttur. Günümüzde 15 yıllık sağkalım \%93-\%100 arasında değişmektedir (Şekil 5 ve 6). ${ }^{[30,31]}$

Komponentlerin eklem yüzeylerinin daha poroz şekilde imal edildiği ve kemiğin protez yüzeyine büyümesi sayesinde tutunumun sağlandığı tasarımlar ise çimentosuz uygulanabilmektedir. Özellikle genç hastalarda, cerrahi süresini kısaltması ve olası gevşemeye bağlı revizyonlarda kemik stoğunun korunabilmesi nedeniyle popüler olmaya başlamıştır. Önceleri sadece AÇB

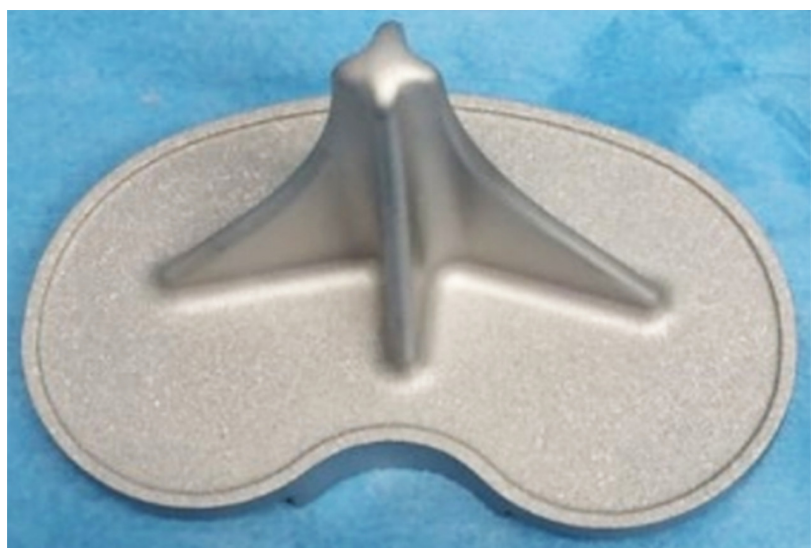

Şekil 6. Çimentolu tibial komponent kemik yüzeyi. 
koruyan modelleri mevcut bu tasarımların, teknolojik gelişmeler ışığında AÇB kesen modelleri de üretilmiş ve uygulanmaya başlanmıştır. Son dönemlerde kemik yüzey büyümesinin daha etkin olabilmesi için klasik Co-Cr alaşımlar yerinde tantalum kullanılmaya başlanmıştır. Yapılan çalışmalarda, geliştirilmeye hâlâ devam edilen bu modellerin çimentolu modellere üstünlüğü hâlâ gösterilememiştir. ${ }^{[32]}$

\section{TOTAL DIZ PROTEZLERINDE ÖZEL TASARIMLAR VE GELECEK}

Uygulanan diz protezi sayısı arttıkça, mevcut implantlardaki yetersizlikler tespit edildikçe, gelişen teknolojinin de yardımıla yeni tasarımlar, yeni materyaller ve yeni sistemler oluşturulmaya devam edecektir. Son dönemde endüstriyel markette kendine yer bulan, zamanla kullanım oranı artan çeşitli diz protezi tipleri mevcuttur

Son dönemde ismini daha sık duyduğumuz ve kullanım oranının arttığı yüksek fleksiyon kapasiteli (highflex) diz protezi bunlardan biridir. Bu yüksek fleksiyon derecesi, posterior femoral kondilin çapı ve genişliğinin artırılması sayesinde elde edilir. Fleksiyon aralığını standart diz protezlerine göre $10^{\circ}-13^{\circ}$ kadar artırdığı gösteren çalışmalar mevcuttur. ${ }^{[33,34]}$ Hasta memnuniyetinde fleksiyon aralığının genişliği çok önemlidir fakat bu açının miktarı tartışmalıdır. Yapılan çalışmalar$\mathrm{da}, 90^{\circ}$ fleksiyonun üzerinde bir açıya, 1.000 hastanın sadece beşinde ihtiyaç duyulduğu gösterilmiştir. Bu nedenle bu tip protezlerin klinik olarak etkisi tartışmaya açıktır. ${ }^{[35]}$

Bir diğer gelişme cinsiyete özgü protez tasarımların kullanılmasıyla gerçekleşmiştir. Kadınların femoral kondilleri erkeklere göre dardır. Standart ölçümler ön-arka düzleme göre yapıldığından bazı durumlarda normalden daha geniş bir femoral komponenet kullanmak zorunda kalınmaktadır. Bunu dengelemek için femoral komponent küçültüldüğünde ise fleksiyonda gevşeklik gözlenmektedir. Cinsiyet spesifik protezler bu uyumsuzluğu giderecek şekilde tasarlanmışlardır, fakat yapılan çalışmalarda klinik sonuçları standart tasarımlara göre farklı bulunmamıştır. ${ }^{[36,37]}$

Yapılan biyomekanik çalışmalar, fleksiyon esnasında lateral femoral kondilin yaklaşı $2 \mathrm{~cm}$ kadar posteriora kaydığını buna rağmen medial femoral kondilin çok az hareket ettiğini göstermiştir. Medial pivot hareketi olarak tanımlanan bu fenomen standart diz protezlerinde tam olarak yoktur. Bu fonksiyon için medial femoral kondili daha yuvarlak olarak tasarlanmış medial pivot diz protezi sistemleri geliştirilmiştir. Doğal diz mekaniğine daha yakın olan bu tasarımlarla yapılan çalışmalar ümit vericidir. ${ }^{[38,39]}$
Son dönemde implant geliştiricilerin üzerinde durdukları bir başka konu sistemik etkilerdir. Diz protezi uygulamalarında hatırı sayılı bir oranda görülen metal sensitivitesi ciddi bir protez komplikasyonu olarak göze çarpmaktadır. Bu noktada geliştirilmiş zirkonyum nitrit ( $\mathrm{ZrN})$ kaplı hipoalerjenik implantların geleneksel implantlara nazaran daha az il-8 ve il-10 salınımına neden olduğu gösterilmiştir. ${ }^{[40]}$ Fakat ileriye dönük çalışmaların yapılması elzemdir.

Diz protezinin olmazsa olmazı komponentlerin nizami bir pozisyonda implante edilmesidir. Günümüzde pozisyon bozukluğu hâlâ çok ciddi bir problemdir. Standart diz protezlerinin hata payı hâlâ yüksektir. Bu noktada son dönemde popülerliği artmaya başlayan navigasyon sistemleri ve robotik cerrahi, cerrahi kusurları minimalize etmektedir.

\section{KAYNAKLAR}

1. Rakhorst G, Ploeg R. Biomaterials in Modern Medicine: the Groningen Perspective: World Scientific; 2008. Crossref

2. Nam D, Nunley R, Barrack R. Patient dissatisfaction following total knee replacement: a growing concern? Bone Joint J 2014;96-B(11_Suppl_A):96-100. Crossref

3. Bourne RB, Chesworth BM, Davis AM, Mahomed NN, Charron KD. Patient satisfaction after total knee arthroplasty: who is satisfied and who is not? Clin Orthop Relat Res 2010;468(1):57-63. Crossref

4. Williams DF. Definitions in biomaterials: proceedings of a consensus conference of the European Society for Biomaterials. Chester, England, March 3-5, 1986: Elsevier Science Limited; 1987.

5. Bahraminasab M, Hassan MR, Sahari BB. Metallic biomaterials of knee and hip -a review. Trends Biomater Artif Organs 2010;24(2):69-82.

6. Carr BC, Goswami T. Knee implants -Review of models and biomechanics. Mater Des 2009;30(2):398-413. Crossref

7. Smallman RE, Bishop RJ. Modern physical metallurgy and materials engineering. Elsevier Ltd.: Butterworth-Heinemann; 1999. Crossref

8. Alvarado J, Maldonado R, Marxuach J, Otero R. Biomechanics of hip and knee prostheses. Applications of Engineering Mechanics in Medicine 2003:6-22. https://cnx.org/resour ces/03e411875fa8570732dfcf1a02b97027d60470ea/27Reading\%20-\%20Goyal.pdf

9. Ramsden JJ, Allen DM, Stephenson DJ, Alcock JR, Peggs G, Fuller G, Goch G. The design and manufacture of biomedical surfaces. CIRP Annals 2007;56(2):687-711. Crossref

10. Davis JR. ASM Specialty Handbook: Stainless steels. US: ASM international; 1994.

11. Navarro M, Michiardi A, Castano O, Planell J. Biomaterials in orthopaedics. J R Soc Interface 2008;5(27):1137-58. Crossref

12. Eisenbarth E, Velten D, Müller M, Thull R, Breme J. Biocompatibility of $\beta$-stabilizing elements of titanium alloys. Biomaterials 2004;25(26):5705-13. Crossref

13. Singh R, Dahotre NB. Corrosion degradation and prevention by surface modification of biometallic materials. J Mater Sci Mater Med 2007;18(5):725-51. Crossref 
14. Nag S, Samuel S, Puthucode A, Banerjee R. Characterization of novel borides in $\mathrm{Ti}-\mathrm{Nb}-\mathrm{Zr}-\mathrm{Ta}+2 \mathrm{~B}$ metal-matrix composites. Mater Charact 2009;60(2):106-13. Crossref

15. Bal BS, Garino J, Ries M, Oonishi $\mathrm{H}$. Ceramic bearings in total knee arthroplasty. J Knee Surg 2007;20(4):261-70. Crossref

16. Blunn G, del Preva EMB, Costa L, Fisher J, Freeman MAR. Ultra high molecular-weight polyethylene (UHMWPE) in total knee replacement: fabrication, sterilisation and wear. J Bone Joint Surg Br 2002;84-B(7):946-9. Crossref

17. Utzschneider S, Harrasser N, Schroeder C, Mazoochian F, Jansson $\mathrm{V}$. Wear of contemporary total knee replacements-a knee simulator study of six current designs. Clin Biomech 2009;24(7):583-8. Crossref

18. Fehring TK, Murphy JA, Hayes TD, Roberts DW, Pomeroy DL, Griffin WL. The Coventry Award Paper: Factors Influencing Wear and Osteolysis in Press-Fit Condylar Modular Total Knee Replacements. Clin Orthop Relat Res 2004;428:40-50. Crossref

19. Freeman MAR, Swanson SAV, Todd RC. Total replacement of the knee using the Freeman-Swanson knee prosthesis. Clin Orthop Relat Res 1973;(94):153-70. Crossref

20. Scott RD, Volatile TB. Twelve years' experience with posterior cruciate-retaining total knee arthroplasty. Clin Orthop Relat Res 1986;(205):100-7. Crossref

21. Simmons $S$, Lephart $S$, Rubash $H$, Borsa P, Barrack RL. Proprioception following total knee arthroplasty with and without the posterior cruciate ligament. J Arthroplasty 1996;11(7):763-8. Crossref

22. Yamakado K, Worland RL, Jessup DE, Diaz-Borjon E, Pinilla R. Tight posterior cruciate ligament in posterior cruciateretaining total knee arthroplasty: A cause of posteromedial subluxation of the femur. J Arthroplasty 2003;18(5):570-4. Crossref

23. Song E-K, Lim H-A, Joo S-D, Kim S-K, Lee K-B, Seon J-K. Total knee arthroplasty using ultra-congruent inserts can provide similar stability and function compared with cruciateretaining total knee arthroplasty. Knee Surg Sports Traumatol Arthrosc 2017;25(11):3530-5. Crossref

24. Kleinbart FA, Bryk E, Evangelista J, Scott WN, Vigorita VJ. Histologic comparison of posterior cruciate ligaments from arthritic and age-matched knee specimens. J Arthroplasty 1996;11(6):726-31. Crossref

25. Knight LA, Pal S, Coleman JC, Bronson F, Haider H, Levine DL, Taylor M, Rullkoetter PJ. Comparison of long-term numerical and experimental total knee replacement wear during simulated gait loading. J Biomech 2007;40(7):15508. Crossref

26. Abdel MP, Tibbo ME, Stuart MJ, Trousdale RT, Hanssen $A D$, Pagnano MW. A randomized controlled trial of fixedversus mobile-bearing total knee arthroplasty: a follow-up at a mean of ten years. Bone Joint J 2018;100-B(7):925-9. Crossref

27. Woolson ST, Epstein NJ, Huddleston JI. Long-term comparison of mobile-bearing vs fixed-bearing total knee arthroplasty. J Arthroplasty 2011;26(8):1219-23. Crossref
28. Ferguson KB, Bailey O, Anthony I, James P, Stother IG, Blyth MJG. A prospective randomised study comparing rotating platform and fixed bearing total knee arthroplasty in a cruciate substituting design-outcomes at two year follow-up. Knee 2014;21(1):151-5. Crossref

29. Watanabe T, Tomita T, Fujii M, Hashimoto J, Sugamoto $\mathrm{K}$, Yoshikawa $\mathrm{H}$. Comparison between mobile-bearing and fixed-bearing knees in bilateral total knee replacements. Int Orthop 2005;29(3):179-81. Crossref

30. Nugent M, Wyatt MC, Frampton CM, Hooper GJ. Despite improved survivorship of uncemented fixation in total knee arthroplasty for osteoarthritis, cemented fixation remains the gold standard: an analysis of a national joint registry. J Arthroplasty 2019;34(8):1626-33. Crossref

31. Scuderi GR, Insall JN, Windsor RE, Moran MC. Survivorship of cemented knee replacements. J Bone Joint Surg Br 1989;71$B(5): 798-803$. Crossref

32. Zhou K, Yu H, Li J, Wang H, Zhou Z, Pei F. No difference in implant survivorship and clinical outcomes between fullcementless and full-cemented fixation in primary total knee arthroplasty: a systematic review and meta-analysis. Int J Surg 2018;53:312-9. Crossref

33. Wong JM, Khan WS, Chimutengwende-Gordon M, Dowd GSE. Recent advances in designs, approaches and materials in total knee replacement: literature review and evidence today. J Perioper Pract 2011;21(5):165-71. Crossref

34. Huang H-T, Su JY, Wang G-J. The early results of high-flex total knee arthroplasty: a minimum of 2 years of follow-up. J Arthroplasty 2005;20(5):674-9. Crossref

35. Huddleston JI, Scarborough DM, Goldvasser D, Freiberg AA, Malchau H. 2009 Marshall Urist Young Investigator Award: how often do patients with high-flex total knee arthroplasty use high flexion? Clin Orthop Relat Res 2009;467(7):1898906. Crossref

36. Thomsen MG, Husted H, Bencke J, Curtis D, Holm G, Troelsen A. Do we need a gender-specific total knee replacement? A randomised controlled trial comparing a high-flex and a gender-specific posterior design. J Bone Joint Surg $\mathrm{Br}$ 2012;94-B(6):787-92. Crossref

37. Tanavalee A, Rojpornpradit T, Khumrak S, Ngarmukos S. The early results of gender-specific total knee arthroplasty in Thai patients. Knee 2011;18(6):483-7. Crossref

38. Karachalios T, Roidis N, Giotikas D, Bargiotas K, Varitimidis S, Malizos KN. A mid-term clinical outcome study of the Advance Medial Pivot knee arthroplasty. Knee 2009;16(6):484-8. Crossref

39. Amin A, Al-Taiar A, Sanghrajka AP, Kang N, Scott G. The early radiological follow-up of a medial rotational design of total knee arthroplasty. Knee 2008;15(3):222-6. Crossref

40. Thomas $P$, Hisgen $P$, Kiefer $H$, Schmerwitz $U$, Ottersbach $A$, Albrecht D, Summer B, Schinkel C. Blood cytokine pattern and clinical outcome in knee arthroplasty patients: comparative analysis 5 years after standard versus "hypoallergenic" surface coated prosthesis implantation. Acta Orthop 2018;89(6):646-51. Crossref 